\title{
Investigating the Performance of Chosen Models for the Estimation of Global Solar Radiation on Horizontal Surface - A Case Study in Terny Hdiel, Tlemcen of Algeria
}

\author{
Aicha Soufi ${ }^{1, *}$, Ali Chermitti ${ }^{1}$, Bouzaki Mohamed Mostafa ${ }^{1}$ and Allam Zehor ${ }^{1}$ \\ ${ }^{1}$ URMER Research unit, Faculty of Sciences, University of Abou-bekr Belkaid, Tlemcen, Algeria
}

Received 20 March 2014; Accepted 29 July 2014

\begin{abstract}
Any study or application of solar energy in a given site requires a complete and detailed knowledge of the available solar resources. Hence, the aim of this work is to evaluate global solar radiation on a horizontal surface in Teny Benu-Hdiel, Tlemcen, Algeria (latitude $34^{\circ} 46^{\prime} 60^{\prime \prime} \mathrm{N}$, longitude $\left.1^{\circ} 22^{\prime} 0^{\prime \prime} \mathrm{E}\right)$ using measured meteorological data. The data were recorded in the period 1983 to 2005 using NASA's surface meteorology and solar energy-model. From these models, the new empirical constants have been obtained for Teny Benu-Hdiel. The selected models give very good results with the exception of second model (Quadratic model).

Moreover, The results showed that the correlation of global solar radiation with sunshine hours, air temperature, relative humidity gives very accurate estimates for selected location $(\mathrm{R} 2=0.997)$.

Further to this, the global solar radiation values created for this study can be used in the designed and optimized performance of a stand-alone photovoltaic system for agricultural applications.

Keywords: Solar energy, Solar radiation models Estimation, Air temperature, Humidity relative, Sunshine duration,Terni Beni hdiel, Tlemcen
\end{abstract}

\section{Introduction}

The great challenge for agriculture activities is meet their energy needs. Solar energy, like other renewable is one of the most interesting uses. It provides electricity directly and independently with reliable equipment and duration of relatively high life for reduced maintenance. Add to that, of its characteristics decrease pollution and greenhouse gases, clean, cost-free, and they are abundant.

What makes this recent favorable to various facets of human energy needs, autonomy, reliability and sustainability in economic terms, they can also provide real solutions, such as public and domestic lighting, pumping water for drinking and irrigation, Livestock, etc.

To make the most of solar PV and a good design of solar systems, it is essential to assess the potential of solar energy available at a specific location at any time of the day and year. However, the majority of the cases, there is no local measurements of sunshine, and solar flux, therefore we must resort to some approximate methods to predict the characteristics of solar radiation. Thus, various existing models have been developed by different researchers for predict solar radiation were formulated based on available geographic and meteorological parameters such as minimum and maximum temperature, solar radiation hours, relative moisture, elevation, rainfall, wind speed and etc. There is numerous models related global solar radiation to sunshine hours. (Soler A 1990 [1], Newland F J A 1988[2], Chegaar M Chibani A 2001[3], Ulgen K and Hepbasli A 2002[4], Togrul I T and Togrul H 2002[5], Ulgen and Hepbasli

*E-mail address: soufiaicha84@yahoo.fr

ISSN: 1791-2377@ 2014 Kavala Institute of Technology. All rights reserved.
2004[6]). (Raja I A 1990[7], Akinoglu and Ecevit 1990[8], Rensheng and Shihua 2006[9], Bakirci 2007[10], Burari and Sambo (2001) [11]. Moreover, Jonathan K. Yohanna et al. (2011) [12] presented a linear form of the AngstromPrescott model to estimate global solar radiation at on a horizontal surface for Makurdi, Nigeria (Latitude $7^{\circ} 70^{\prime} \mathrm{N}$ and Longitude $\left.8^{\circ} 60^{\prime} \mathrm{E}\right)$. They concluded that the month of March, which had the highest solar radiation of $264 \mathrm{~W} / \mathrm{m} 2$ also had the highest hour of bright sunshine of $7.7 \mathrm{~h}$, while the lowest solar radiation of $169 \mathrm{~W} / \mathrm{m} 2$ and bright sunshine hours of $4.8 \mathrm{~h}$ was in August.

Further to this, a number of researchers related global solar radiation to air temperature for the estimation of the available solar irradiance. Of these models:, Hergreaves and Samani proposed an correlation between clearness index and the square root of the temperature term difference $\Delta T$. E O Ogolo 2010 [13] used both linear and polynominal regression technique to develop somme predictive models classified as sunshine hours and temperature dependent for estimation of global solar radiation for four tropical stations in Negeria. Ituen et al. (2012) [14] evaluated various models to predict the monthly global solar radiation used the measured data of air temperature, relative humidity and sunshine hour for Uyo, in Niger Delta Region, Nigeria during the period (1991-2007). Chandel et al. (2005) [15] proposed a model based on temperature. Yingni Jiang (2009) [16] used an A artificial neural network (ANN) model for the estimation of solar radiation of 8 typical cities in China.

Recently, Javier Almorox et al (2013) [17] presented five models for calculating the global solar radiation on a horizontal surface at Changdu, Geer, Lasa and Naqu stations in Tibet, China, so the parameters used as inputs were based on easily available meteorological variables, without 
sunshine hours as input, and were used to estimate the daily solar radiation at Cañada de Luque (Córdoba, Argentina). According to the authors the results showed a $\mathrm{R}^{2}$ and $\mathrm{RMSE}$ values between 0.87 to 0.89 and 2.05 to 2.14 , respectively. Fariba Besharat et al. (2012) [18] used sunshine hours and temperature measured data to estimating monthly mean daily global solar radiation on a horizontal surface for Yazd city, Iran. Chegaar $M$ and A Chibani [3] have estimated the Global solar radiation for Algeria using the clearness index following the work by Liu and Jordan [19]. These studies led to different models for solar radiation assessment. Moreover, as Terny Beni Hdiel is a village in the rural community Tlemcen (see Figure 1), one from one of the regions which have a very important solar potential in areas of the city of Tlemcen (Algeria) and which has a big importance for the agricultural applications. Its location (3446'60" N longitude 122'0" Altitude $1.229 \mathrm{~m}$ ) [20] it confer significant energy wealth.

The main objective of this study is to investigate the applicability existing solar radiation models at Terny Beni Hdiel, Tlemcen in Algeria, where no study has been published yet for this village. We used the sunshine duration, Humidity relative and air temperature as input parameters. These parameters were obtained from the archives of National Aeronautics and Space Administration (NASA) [21] for a 22-year period (1983-2005).

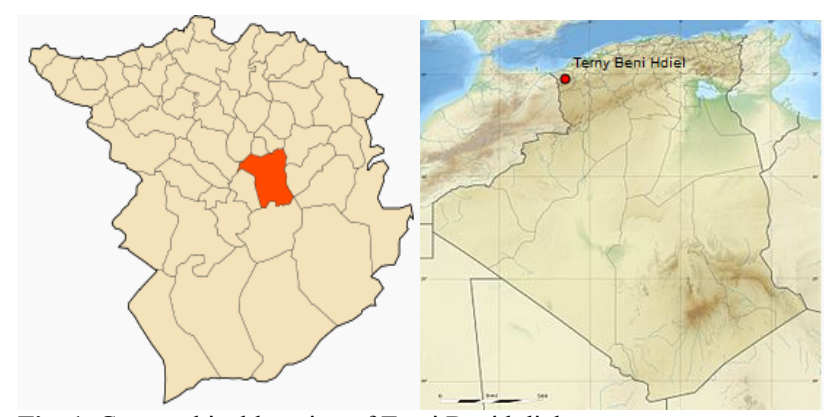

Fig. 1. Geographical location of Terni Beni hdiel.

\section{Description of the models used}

Various empirical correlations which establish the relation between solar radiation and various meteorological parameters were reported in the literature. In this study, five representative models were chosen for the estimation of the global solar radiation on horizontal surface for Terny Beni Hdiel, Tlemcen in Algeria.

The first model (M1) is the Angstrom-Prescott [22], so Angstrom (1924) proposed first empirical relation for GSR estimation based on applying sunshine hours for a long time. Prescott (1940) modified Angstrom model and is known as Angstrom-Prescott model. Page (1961) gave the coefficients of the Angstrom-Prescott model, which is believed to be applicable any place in the world.

$\frac{\bar{H}}{\overline{H_{0}}}=a+b\left(\bar{S} / \overline{S_{0}}\right)$

Where,

$\mathrm{K}_{\mathrm{T}}=\frac{\bar{H}}{\overline{H_{0}}}$ monthly mean clearness index

$\mathrm{H}$ monthly average daily global radiation on a horizontal surface $\left(\mathrm{KWh} / \mathrm{m}^{2}\right.$.day)
$\mathrm{H}_{0} \quad$ monthly average daily extraterrestrial radiation

$\left(\mathrm{KWh} / \mathrm{m}^{2}\right.$.day)

$\mathrm{S}$ monthly average daily hours

$\mathrm{S}_{0} \quad$ monthly average day length (h)

$\mathbf{a}$ and $\mathbf{b}$ are empirical coefficients.

The second model (M2) suggested by Akinoglu and Ecevit [23] is described by the following quadratic equation:

$\frac{\bar{H}}{\overline{H_{0}}}=a+b\left(\bar{S} / \overline{\mathrm{S}_{0}}\right)+\mathrm{c} b\left(\bar{S} / \overline{\mathrm{S}_{0}}\right)^{2}$

El-Sebaii et al. (2009) [24] compared some existing models (Sen (2007) [25], Bulut (2007) [26]) used for estimating of global solar radiation on horizontal surfaces in Jeddah, Saudi Arabia based on humidity relative and temperature. Therefore, the third order model (M3) is described by the following quadratic equation:

$\frac{\bar{H}}{\overline{H_{0}}}=a+b\left(\bar{S} / \overline{S_{0}}\right)+\mathrm{c} T$

\section{Where $\mathrm{T}$ is Air Temperature}

The fourth model (M4) proposed in [27], [28] follows the equation

$\frac{\bar{H}}{\bar{H}_{0}}=a+b\left(\bar{S} / \overline{\mathrm{S}_{0}}\right)+\mathrm{c} R$

$\mathrm{R}$ is monthly mean relative humidity (\%)

The five model (M5) [29] has as an equation:

$\overline{\bar{H}}=a+b\left(\bar{S} / \overline{\mathrm{S}_{0}}\right)+\mathrm{c} T+\mathrm{d} R$

The monthly average daily extraterrestrial radiation on a horizontal surface can be computed from the following equation [30];

$H_{0}=\frac{24}{\pi} I_{s c}\left[1+0.033 \cos \frac{360 n}{365}\right]\left[\cos \emptyset \cos \delta \sin w_{s}+\right.$ $\left.\frac{\pi}{180} w_{s} \sin \emptyset \sin \delta\right]$

$\Phi \quad$ latitude of the site

Isc solar constant $\left(1367 \mathrm{Wm}^{-2}\right)$

$\delta=23.45 \sin \left[\frac{360(284+n)}{365}\right]$

$w_{s}=\cos ^{-1}(-\tan \emptyset \tan \delta)$

Where $\delta$ is solar declination in degrees, $\mathrm{n}$ is number of days and $\omega_{\mathrm{s}}$ mean sunrise hour angle

$S_{0}=\left(\frac{2}{15}\right) \cos ^{-1}(-\tan \emptyset \tan \delta)$

\section{Methods of models evaluation}

The accuracy of these models was evaluated by calculating statistical tests like Mean Percentage Error (MPE), Root Mean Square Error (RMSE), Mean Bias [31], [32]. These statistical expressions used in this study are in the above equations: 
$M B E=\frac{\sum_{1}^{\mathrm{n}}\left(\mathrm{H}_{\mathrm{cal}}-\mathrm{H}_{\text {meas }}\right)}{\mathrm{n}}$

$R M S E=\sqrt{\frac{1}{n} \sum_{1}^{n}\left(H_{c a l}-H_{e s t}\right)^{2}}$

$M P E=\frac{1}{\mathrm{n}} \sum_{1}^{\mathrm{n}} \frac{\left(\mathrm{H}_{\mathrm{cal}}-\mathrm{H}_{\text {meas }}\right)}{\mathrm{H}_{\text {meas }}} * 100$

\section{Results and Discussion}

In order to estimate the global solar radiation for Terny Beni-Hdiel using five empirical regression between clearness index $\left(K=\frac{\bar{H}}{\overline{H_{0}}}\right)$ and meteorological parameters, a computer program was written to evaluate the values of the regression coefficients $a, b$, c,and $d$ using the data of the selected location.

In this paper, the monthly average data of daily Global solar radiation, sunshine hours, Air temperature and relative humidity for Terny Beni-Hdiel for the period 1983-2005 [21] are exploited. The meteorological data needed for this study are in Table 1.

From the computer program, the following relationship is established to evaluate monthly average daily global radiation on horizontal surface

Table 1: Sunshine hours $(\bar{S})$, air temperature $\left(\mathrm{T}_{\text {Air }}\right)$, and relative humidity $(\mathrm{R})$ for Terny beni-hdiel area.

\begin{tabular}{c|c|c|c}
\hline Month & $\mathbf{R}(\mathbf{\%})$ & $\overline{\boldsymbol{S}}(\boldsymbol{H} \boldsymbol{r})$ & $\boldsymbol{T}\left({ }^{\circ} \boldsymbol{C}\right)$ \\
\hline Jan. & 60.8 & 10.1 & 7.90 \\
Feb. & 54.7 & 10.9 & 9.82 \\
Mar. & 48.3 & 11.9 & 12.9 \\
Apr & 43.3 & 13.0 & 15.5 \\
May & 41.3 & 13.9 & 19.6 \\
Jun & 35.7 & 14.4 & 24.5 \\
Jul & 31.4 & 14.2 & 27.9 \\
Aug & 35.4 & 13.4 & 27.4 \\
Sep & 45.4 & 12.4 & 23.2 \\
Oct & 49.2 & 11.3 & 18.6 \\
Nov & 56.9 & 10.3 & 13.0 \\
Dec & 60.5 & 9.88 & 9.31 \\
\hline
\end{tabular}

The results of these analyses can be seen as the following equations presented in table 2 . The values of the regression constants $\mathrm{a}, \mathrm{b}$ and $\mathrm{c}$ for Terny Beni-Hdiel using the non linear model (El-Sebaii et al. (2009)) are obtained as $1.9385,-1.2015$ and -0.304 respectively. Additionally, the result of the analysis from model 3 using the air temperature and fraction of sunshine values shows the regression coefficients $4.495,-3.9240$ and 0.0032 .

Table 2. Evaluation of the regression constants for the five developed models

\begin{tabular}{c|l|l|l|l}
\hline Model & a & b & c & d \\
\hline 1 (Eq.(1)) & -6.421 & 7.0771 & & \\
2 (Eq.(2)) & 253.48 & -5.19 .55 & 266.76 & \\
3 (Eq.(3)) & 4.495 & -3.9240 & 0.0032 & \\
4(Eq.(4)) & 1.9385 & -1.2015 & -0.3044 & \\
5(Eq.(5)) & 1.4515 & -0.6762 & -0.0008 & -0.3710
\end{tabular}

Measurements of the the monthly averaged Air Temperature at $10 \mathrm{~m}$ above the surface of the earth, Sunshine hours and the monthly averaged relative humidity for Terni Beni-Hdiel vilage in Tlemcen (Algeria) are illustrated in Fig. 2 .

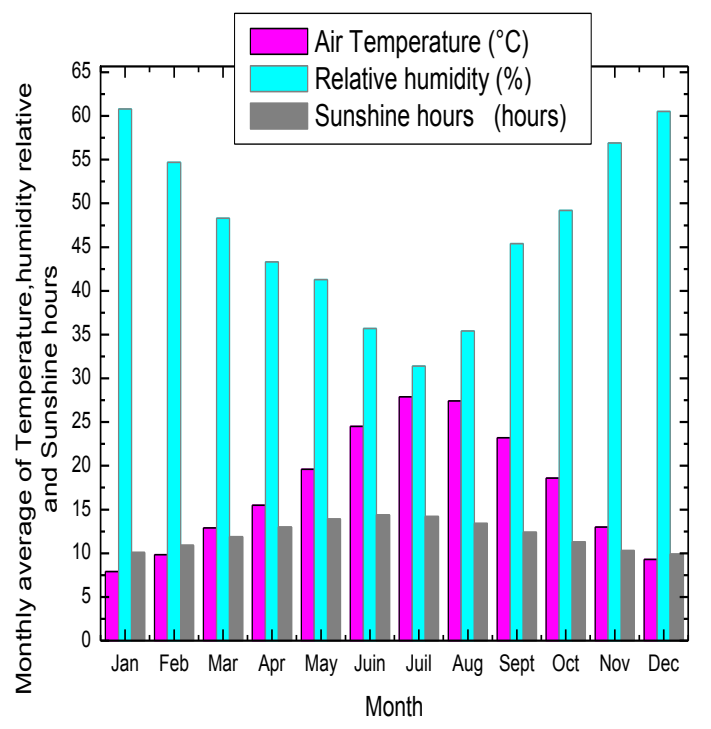

Figu. 2. Monthly air temperature and Monthly humidity relative of the proposed site.

The comparison bestween the estimated value using the various models, with the measured values is given in Table3.

Table 3. Measured and estimated values of Monthly average daily global irradiation on horizontal surface in $\left(\mathrm{KWh} / \mathrm{m}^{2}\right.$.day) for Terny Beni-Hdiel village.

\begin{tabular}{|c|c|c|c|c|c|c|}
\hline \multirow{2}{*}{$\begin{array}{c}\text { Mont } \\
\mathbf{h}\end{array}$} & \multirow{2}{*}{$\begin{array}{c}\text { Mesure } \\
\text { d } \\
\text { Global } \\
\text { solar } \\
\text { radiatio } \\
\text { n } \bar{H}\end{array}$} & \multicolumn{5}{|c|}{ Estimated Globel solar radiation $\overline{\boldsymbol{H}}$} \\
\hline & & $\begin{array}{l}\text { Model } \\
1\end{array}$ & $\begin{array}{l}\text { Model } \\
2\end{array}$ & $\begin{array}{l}\text { Model } \\
3\end{array}$ & $\begin{array}{l}\text { Model } \\
4\end{array}$ & $\begin{array}{l}\text { Model } \\
5\end{array}$ \\
\hline Jan & 2.82 & 2.8539 & 4.9483 & 2.7463 & 2.7304 & 2.7298 \\
\hline Feb & 3.73 & 3.7905 & 5.8009 & 3.6338 & 3.6297 & 3.6325 \\
\hline Mar & 4.67 & 4.8632 & 7.1621 & 4.7226 & 4.7712 & 4.7850 \\
\hline Apr & 5.87 & 5.9598 & 8.3882 & 5.8392 & 5.9298 & 5.9514 \\
\hline May & 6.64 & 6.8891 & 8.6227 & 6.8012 & 6.7155 & 6.6971 \\
\hline Jun & 7.23 & 7.0285 & 9.2897 & 7.1664 & 7.1458 & 7.1349 \\
\hline Jul & 7.30 & 6.7966 & 9.3167 & 7.0855 & 7.1245 & 7.1217 \\
\hline Aug & 6.32 & 6.1785 & 8.7573 & 6.4535 & 6.4081 & 6.3877 \\
\hline Sep & 5.13 & 4.8975 & 8.6706 & 5.1580 & 5.1267 & 5.1108 \\
\hline Oct & 3.92 & 3.7875 & 7.1936 & 3.9216 & 3.9621 & 3.9647 \\
\hline Nov & 2.90 & 3.0991 & 5.0163 & 3.0463 & 2.9756 & 2.9611 \\
\hline Dec & 2.50 & 2.5598 & 4.8179 & 2.5098 & 2.5087 & 2.5095 \\
\hline
\end{tabular}

The measured and estimated values of the monthly average daily global radiation on horizontal surface using models selected for Terny Beni hdiel vilage are illustrated in Figure 3. At the first view, it was seen that a small divergence between the values estimated and measured during all months, while the five models have a little deviation between their results and the observed values. Also, it is clear that model (M1), (M3), (M4) and (M5) shows a very good agreement with measured data[20]. 


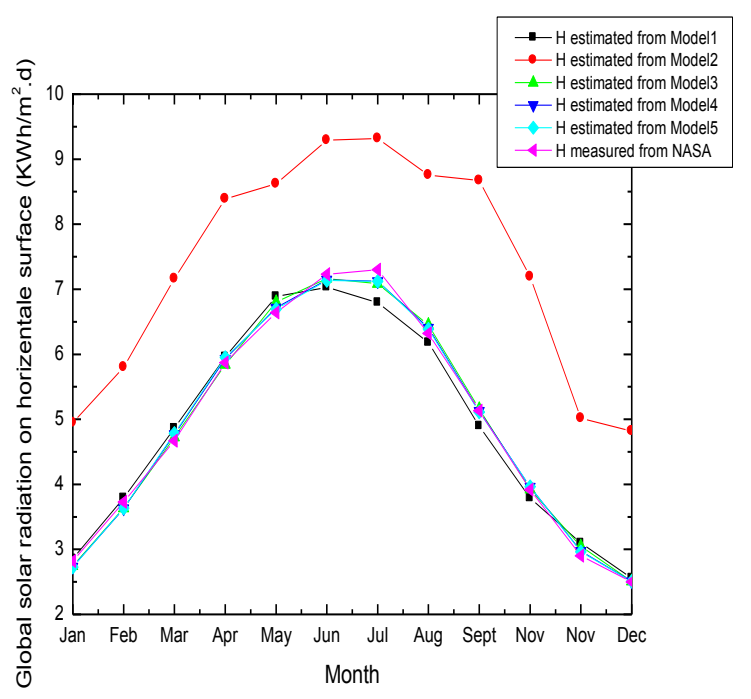

Fig. 3. Measured and estimated values of Global solar radiation on horizontal surface by different models for selected area.

The calculation for global solar radiation in the selected models are the polynomial function of clearness index Kt.

In figure 4, the variation of the estimated $\mathrm{Kt}$ values in the proposed area is presented. It can be seen that the monthly average values of clearness index for Terni Beni-Hdiel do not exceed the value of 0.56 (Model1, Model3, Model4 and Model5), As for the second model, when we use the sunshine duration, as impute the $\mathrm{Kt}$ values varies from 0,9668 to 1,0207 .

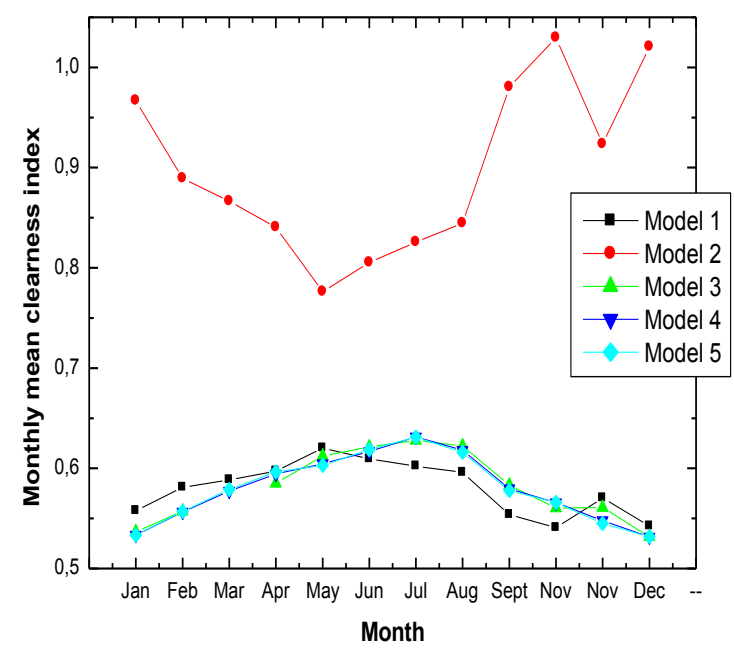

Fig. 4. Evolution of Monthly mean clearness index for months of the year for the selected model (1-5)

Figure 5 shows the correlation between the predicted values by empirical models (1-5) and measured values of the global solar radiation on horizontal surface. It is obvious from this figure that the comparison of the models $1,3,4$, and 5 give a fairly good agreement between estimated and observed values.

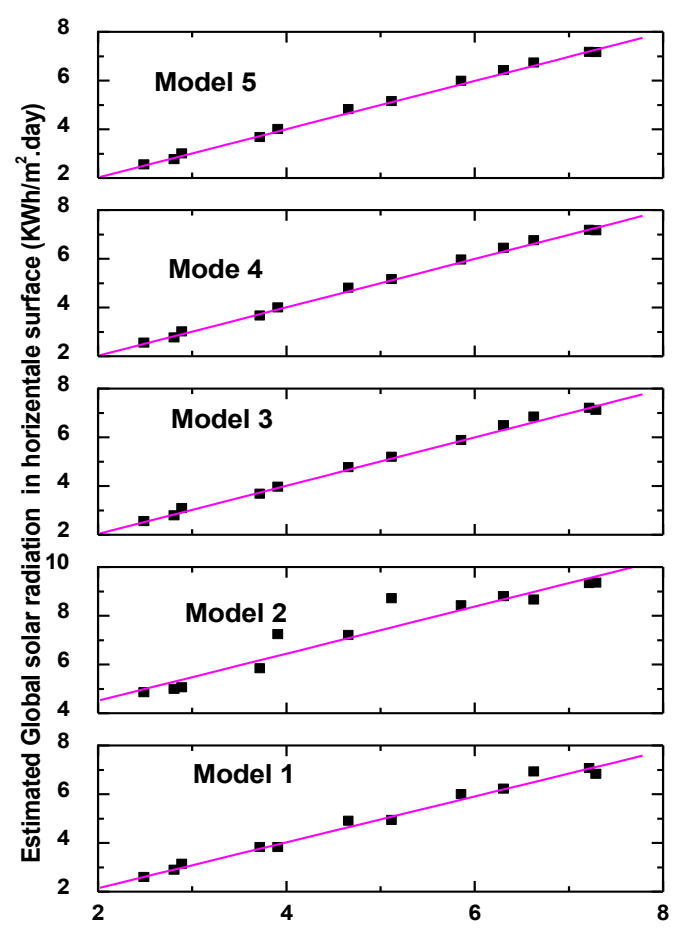

Measured Globalsolar radiation in horizentale surface $\left(\mathrm{KWh} / \mathrm{m}^{2}\right.$.day)

Fig. 5. The measured and estimated (by five models) values of monthly average daily global solar radiation for terny Beni-Hdiel.

The performance of the five models was evaluated in terms of RMSE, MBE, MPE and $\mathrm{R}^{2}$; the statistical results of selected models are given in Table 4.

Table 4. Statistical test for global solar radiation of selected Models

\begin{tabular}{|c|c|c|c|c|}
\hline Equation Models & $\begin{array}{l}\text { MBE(kWh } \\
\left./ \mathbf{m}^{2} . d\right)\end{array}$ & $\begin{array}{l}\text { RMSE(( } \\
\mathrm{kWh} / \mathrm{m}^{2} \text {. } \\
\text { d) }\end{array}$ & MPE(\%) & $\mathbf{R}^{2}$ \\
\hline 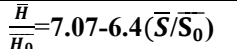 & -0.0272 & 0.2124 & -0.046 & 0.985 \\
\hline $\begin{array}{l}\frac{\bar{H}}{\overline{H_{0}}}=253.48- \\
519.55\left(\overline{S_{S}} / \overline{S_{0}}\right)+266.1 \\
6\left(\bar{S} / \overline{S_{0}}\right)^{2}\end{array}$ & 2.412 & 2.460 & 4.087 & 0.911 \\
\hline $\begin{array}{l}\frac{\bar{H}}{\overline{H_{0}}}=4.495+- \\
3.924\left(\bar{S} / \overline{S_{0}}\right)+0.0032\end{array}$ & 0.0049 & 0.1056 & 0.0083 & 0.995 \\
\hline $\begin{array}{l}\mathbf{T}_{\text {air }} \\
\stackrel{H}{\overline{H_{0}}}=2.24-1.49\left(\overline{\boldsymbol{S}} / \overline{\mathbf{S}_{\mathbf{0}}}\right)- \\
0.33 \mathrm{R}\end{array}$ & -0.00015 & 0.087 & -0.00026 & 0.997 \\
\hline $\begin{array}{l}\overline{\bar{H}}=1.4518- \\
\overline{H_{0}} \\
0.6762\left(\bar{S} / \overline{S_{0}}\right)- \\
0.0008 T_{\text {air }}-0.3710 R\end{array}$ & -0.0037 & 0.093 & -0.0062 & 0.997 \\
\hline
\end{tabular}

From the statistical results, it can be seen that the estimated values of monthly mean daily global solar irradiation are in good agreement with the measured values for all models except the second model (M2) suggested by Akinoglu and Ecevit, where the latter has higher MBE values $(\mathrm{MBE}=2.412 \mathrm{kWh} / \mathrm{m} 2 . \mathrm{d})$ for the proposed area. It is interesting to note that a ZERO values for MBE are perfect.

It was found that the mean percentage errors of all the models other than Akinoglu and Ecevit models in the range of acceptable values between- $0.00026 \%$ to $0.0083 \%$, with 
lowest RMSE values ranging from -0.087 to $0.21 \mathbf{k W h} / \mathbf{m}^{2}$.d. Also, the MBE values of all the models other than Glover and $\mathrm{McC}$ Culloch model are very close to zero.

Furthermore, the best result $(\mathrm{R} 2=0.997)$ was derived from the fourth and fifth model, which uses sunshine hours, relative humidity and air temperature as input. The best result $(\mathrm{R} 2=0.995)$ was derived from model 3 , which uses sunshine hours and temperature as predictors, This shows that the model 3 can also be employed for each of the sites of rural area in Tlemcen. The first model, which only uses sunshine hours, was almost as good.

Comparing the statistical errors values for all model selected in this study, we can perceive that the results obtained provide the third, fourth and fifth models with humidity relative and air temperature as inputs as promise for evaluating global solar radiation for Terny Beni-Hdiel region.

\section{Conclusion}

For accurate information of mean monthly values of global radiation at Terny Beni hdiel five models for estimating have been presented in this study. These models are based on the sunshine hours, air temperature and humidity relative data. Furthermore, through the analysis based on statistical error tests, the results showed that with the exception of model 2 , the remaining models performed a good agreement with the measured values, along the best performance by model 3 , due to its accuracy, input requirements and simplicity.

For future work, these results can be used to estimate monthly global solar radiation on tiled surface based on the monthly global solar radiation evaluated on horizontal surface, also these empirical equations with these selected variables were conducted to use in the designed and optimized of performance of a stand-alone photovoltaic system adapted for agricultural applications for Terny BeniHdiel, Tlemcen of Algeria.

\section{References}

1. A Soler Solar Wind Technol 7.305 (1990)

2. J Clerk Maxwell A Treatise on Electricity and Magnetism 3rd ed.Oxford Clarendon pp.68-73 (1892)

3. M Chegaar A Chibani Energy Conversion and Management 42 967-973 (2001)

4. $\mathrm{K}$ Ulgen and A Hepbasli International journal of Energy Research 26 413-430 (2002)

5. İ T Togrul and H Togrul Renewable Energy 25 55-67 (2002)

6. Ulgen K and Hepbasli A Energy Sources 26 521-530 (2004)

7. Raja I A Twidell J W Solar Energy 44 73-76 (1990)

8. Akinoglu B G and Ecevit A Solar Energy 45(2) 85-92 (1990)

9. Rensheng $\mathrm{C}$ et al. Energy Conversion and Management $47865-$ 878 (2006)

10. Bakirci K Journal of Thermal Science and Technology 27(1) 711 ( 2007)

11. Burari and Sambo Nigeria Journal Renewable Energy 9:34-36 (2001)

12. Jonathan K. Yohanna, Isaac N. Itodo,, Victor I. Umogbai, A model for determining the global solar radiation for Makurdi, Nigeria, Renewable Energy 36 (2011)

13. E O Ogolo Indian journal of Radio \&Space Physics Vol. 39 pp 121-131 (2010)

14. Ituen Eno E.,et al Advances in Applied Science Research 3 (4) 1923-1937 (2012)

15. Chandel S S Aggarwal R K and Pandey A N ASME 127 (3) 417-420 (2005)

16. Yingni Jiang Energy Energy $34-1276-1283$ (2009)

17. Javier Almorox Mónica Bocco Enrique Willington Renewable Energy 60 (2013) 382e387 (2013)

18. Fariba Besharat Ali A Dehghan and Ahamd R Faghi International Conference on Solar energy for MENA region (INCOSOL) Amman Jordan October (2012)

19. M Maroof Khan and M Jamil Ahmad Engineering Science and Technology 5 (2) (2012) 12-19 (2012)

20. http://www.earthtools.org/

21. NASA Surface Meteorology and Solar Energy Data and Information http://eosweb.larc.nasa.gov/sse

22. S O UDO Turk J Phys 26229 - 236 (2002)

23. [23] Akinoglu BG, Ecevit A. Construction of a quadraticmodel usingmodified Ångström coefficients to estimate global solar radiation. Solar Energy 1990;45:85-92.

24. El-Sebaii A A Trabea A.A Energy Conversion and Management 44 2471-2482 (2003)

25. Sen Z Renewable Energy 32 342-350 ( 2007)

26. Bulut H Büyükalaca O Applied Energy, 84 477-491 (2007)

27. Abdalla YAG. New correlation of global solar radiation with meteorological parameters for Bahrain. Int $J$ Sol Energy 1994;16:111-20

28. Indira Karakoti, Prasun Kumar Das, S.K. Singh, Predicting monthly mean daily diffuse radiation for India, Applied Energy 91 (2012)
$412-425$

29. F. Antonanzas-Torres, A. Sanz-Garcia, F.J. Martínez-de-Pisón, O. Perpiñán-Lamigueiro, Evaluation and improvement of empirical models of global solar irradiation: Case study northern SpainRenewable Energy, 60 (2013) 604-614

30. Al-Shamisi M and Jama M Proceedings of the 4th International Conference on Renewable Energy Sources (RES'10) pp 109-113 (2010)

31. Isaac Rahimia Bahram Bakhtiarib Kourosh Qaderib Mehrdad Aghababaiec Energy Procedia 18644 - 651 (2012)

32. A M Muzathik1 et al. Mechanical and Materials Engineering (IJMME) Vol. $6 \quad$ p 75 (2011) 